\title{
Calculation of loading ability of power transformers taking into account electromechanical characteristics
}

\author{
D. D. Micu' ${ }^{1}$ A. G. Rusina ${ }^{2}, O . V$. Naumov $^{3, *}$, and A. N. Gorlov ${ }^{4}$ \\ ${ }^{1}$ Technical University of Cluj-Napoca, Cluj-Napoca, Romanian \\ ${ }^{2}$ Novosibirsk State Technical University, Novosibirsk, Russia \\ ${ }^{3}$ Kazan State Power Engineering University, Kazan, Russia \\ ${ }^{4}$ The Southwest State University, Kursk, Russia
}

\begin{abstract}
This paper presents calculation of operation modes of power transformers aiming at determination of optimum loading at which the transformer performance coefficient reaches its maximum. Options for increasing the efficiency of power transformers operation at industrial enterprises are proposed.
\end{abstract}

\section{Introduction}

Effects of economic and energy crisis force to pay attention on assessment of wastage rates of power and electric power and possibility for their reduction by transfer of electrical energy both in general, and in separate elements of an electrical generating system, in particular, in transformers. Growth of electric power losses in power transformers during their aging comparing with the passport data obtained for the year of production is observed. At the same time, as a rule, transformer manufacturers claim that even when electric power losses during operational transformers' use increase, this increase is not more than for $5 \%$ for all service life of the transformer [1].

The conducted researches showed that aging of transformer leads to growth of electric power losses, occasionally it heavily depends on working conditions.

\section{Object of study}

It is known that the rated capacity of transformers in a network "power plant - the consumer of electrical energy" is 10 times more than generating capacities of power plant. At the same time the repeated transformation of electrical energy is connected with its losses, and with other things being equal, the more there are transformation steps, the higher losses are. The standard assessment of efficiency of operation of electrical generating systems is the method of the given expenses [2].

During solution of some narrower tasks other criteria for determination of overall performance of electric equipment can be accepted [3]. The minimum of power losses (electric power) as criterion for the choice of rated capacity of the transformer or extent of its loading can be applied to versions of schemes of power supply with invariable sections and brands of cables, their length, schemes and the equipment installed on substations, etc.

In certain cases it is proposed to consider loading corresponding to maximum performance coefficient [4] as criterion of the transformer optimum loading.

Practically it is difficult to use this criterion as the maximum transformer efficiency with the broad range of change of secondary loading $(k l=0.4-1.5)$ is expressed poorly [5].

\section{Calculation of loading ability of power transformers}

Transformer performance coefficient is relation of the given power $P_{2}$ to power $P_{1}$ coming to the primary winding. The balance equation of transformer network power has the following form [6]:

$$
P_{1}=P_{2}+\Delta P=P_{2}+\Delta P_{s t}+\Delta P_{c},
$$

where $\Delta P_{s t}$ is power loss in steel; $\Delta P_{c}$ is power loss in copper; $\Delta P$ is total power loss; $P_{2}=U_{2} \cdot I_{2} \cos \varphi$ is active power of consumers; $U_{2}$ is tension of the transformer secondary winding; $I_{2}$ is current of transformer secondary winding; $\cos \varphi$ is transformer electrical power factor.

Power losses in magnetic conductor steel driven by hysteresis and whirling currents $\Delta P_{s t}$ depends on amplitude of a magnetic flux and since magnetic flux is constant, the power of losses in steel does not change, and it does not depend on loading for constant supply voltage. These losses are $1-2 \%$ of the rated power of the transformer [7].

Power losses in wires of windings depend on loading as:

$$
\Delta P_{c}=R_{k} I_{1}^{2}
$$

\footnotetext{
* Corresponding author: 311670@list.ru
} 
where $R_{k}$ is resistance of transformer winding; $I_{1}$ is current of the transformer primary winding.

The performance coefficient of transformer can be calculated using expression [8]

$$
\begin{aligned}
& \eta=\frac{P_{2}}{P_{1}}=\frac{P_{2}}{P_{2}+\Delta P_{s t}+\Delta P_{c}}= \\
& =\frac{U_{2} \cdot I_{2} \cos \phi}{U_{2} \cdot I_{2} \cos \phi+\Delta P_{s t}+\Delta P_{c}}
\end{aligned},
$$

From experiences of idling and short circuit we receive $\Delta P_{s t}=\Delta P_{i}$, where $k_{l}=I_{1} / I_{1 \text { nom }}$ is the load factor; $I_{1 \text { nom }}$ is the nominal current of the transformer primary winding.

The performance coefficient can be calculated using expression [9]

$$
\eta=\frac{k_{l} S_{p o t} \cos \varphi_{2}}{k_{l} S_{p o t} \cos \varphi+\Delta P_{i}+k_{l}^{2} \Delta P_{s c}} .
$$

According to (4) it is possible to calculate $k_{l}$ at which the performance coefficient is maximum. Having equated zero a derivative $\mathrm{d} \eta / \mathrm{d} k$, we receive

$$
k_{l}^{2} \Delta P_{s c}=\Delta P_{i} .
$$

Therefore, efficiency has its maximum at equality of power losses in wires of windings and in steel. Therefore, optimum load factor of the transformer is

$$
k_{l}=\sqrt{\frac{\Delta P_{i}}{\Delta P_{s c}}} .
$$

Usually for modern power transformers $\Delta P_{i} / \Delta P_{s c}=0.2-0.3$ and therefore the maximum efficiency is achieved at $k_{l}=0.4-0.5$ [10].

The relationship between efficiency of $400 \mathrm{kVA}$ transformer and load factor at the fixed $\cos \varphi$ is given in Figure 1.

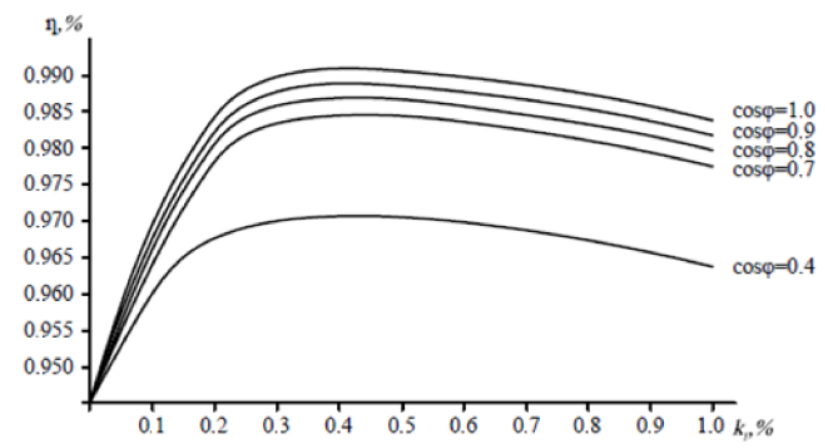

Fig. 1. Relationship between transformer efficiency and load factor for various electrical power factor of loading.

From figure 1 it is seen that the transformer has almost constant efficiency with the broad range of change of loading from 0.5 to 1.0. At low loads and decreased electrical power factor the transformer efficiency sharply decreases.
The dependence of optimum load factor on the rated power of transformers of $10 / 0.4 \mathrm{kV}$ is given in figure 2 , it is seen that at increase in transformer power its optimum load factor decreases.

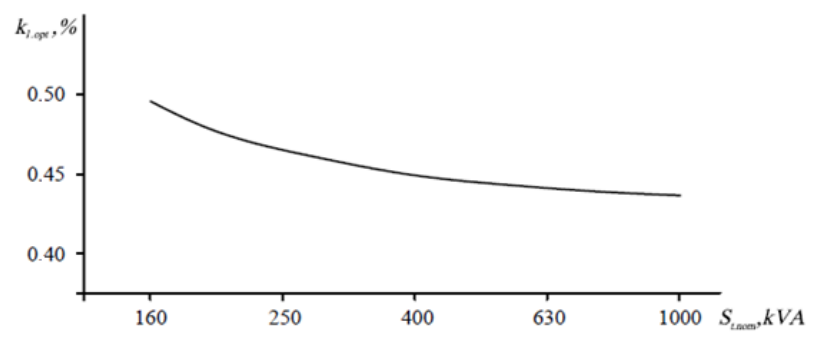

Fig. 2. Relationship between optimum load factor of $10 / 0.4 \mathrm{kV}$ transformer and its rated power.

\section{Conclusions}

The developed nomenclature of the manufactured transformers, taking into account fixed power losses in steel and in copper for each type of the transformer given the set consumption diagram and invariable other elements of an electrical generating system makes it possible to pose the question on the choice of transformer rated power assumed to installation depending on the selected optimality criterion [11].

While considering the question of transformers optimum loading it is necessary to specify that in each specific time point transformer loading is defined by the power of electrical energy receivers connected to its windings that is the diagram of consumption, the nature of technological process [12].

With increasing the transformer load factor from zero its performance coefficient increases up to a certain value, and then goes down. At the same time total power losses only increase. The maximum performance coefficient does not correspond to the minimum power losses [13].

This feature allows one to consider the following options of increase in operation efficiency of transformer substations of industrial enterprises:

1) If the total power consumed by loading is lower than the level of $30-40 \%$ of $S_{p o t}$, as a measure of energy saving one or several transformers are reasonable to disconnect to bring loading of other transformers to optimum value;

2) During replacement of transformers which exhausted its' value or upgrading transformer substations installation of energy efficient transformers with the improved characteristics (such as load losses and losses in steel) as well as the presence of a monitoring and status-diagnosing system of the transformer (Table 1) is preferable;

3) Usage of compensating devices for increasing the performance coefficient of power transformers of the industrial enterprises is inexpedient as increase in efficiency driven by growth of electrical power factor occurs less than for $1-3 \%$ on average.

According to the European standards of harmonization [14, 15], key indicators of power efficiency for power transformers are losses of idling and 
Table 1. Losses of short circuit and idling of power transformers $6(10) / 0.4 \mathrm{kV}$.

\begin{tabular}{|c|c|c|c|c|c|c|c|c|c|c|c|c|}
\hline \multirow[t]{2}{*}{ Factory } & \multirow{2}{*}{\multicolumn{2}{|c|}{$\begin{array}{c}\text { Losses, } \\
\mathrm{kW}\end{array}$}} & \multicolumn{2}{|c|}{$100 \mathrm{kVA}$} & \multicolumn{2}{|c|}{$250 \mathrm{kVA}$} & \multicolumn{2}{|c|}{$400 \mathrm{kVA}$} & \multicolumn{2}{|c|}{$630 \mathrm{kVA}$} & \multicolumn{2}{|c|}{$1000 \mathrm{kVA}$} \\
\hline & & & dry & oil & dry & oil & dry & oil & dry & oil & dry & oil \\
\hline \multirow{2}{*}{$\begin{array}{l}\text { GC "Elektroschit-TM-Samara", } \\
\text { Samara }\end{array}$} & \multicolumn{2}{|c|}{ I } & 550 & 400 & 730 & 580 & 1000 & 830 & 1400 & 1050 & 1950 & 1550 \\
\hline & \multicolumn{2}{|c|}{$\mathrm{SC}$} & 2300 & 2400 & 3700 & 3700 & 4900 & 5900 & 7100 & 7600 & 10000 & 10800 \\
\hline \multirow{2}{*}{$\begin{array}{l}\text { Holding company "Electrozavod", } \\
\text { Moscow }\end{array}$} & & 540 & 290 & 900 & 570 & 1200 & 830 & 1650 & 1060 & 2150 & 1400 \\
\hline & \multicolumn{2}{|c|}{$\mathrm{SC}$} & 1250 & 1970 & 3000 & 3700 & 3900 & 5400 & 5730 & 7450 & 8400 & 10800 \\
\hline \multirow{2}{*}{$\begin{array}{l}\text { "Tolyatti Transformer", } \\
\text { Tolyatti }\end{array}$} & & 420 & 305 & 750 & 610 & 1150 & 900 & 1400 & 1250 & 2000 & 1900 \\
\hline & \multicolumn{2}{|c|}{$\mathrm{SC}$} & 2100 & 2000 & 3700 & 3700 & 5700 & 5500 & 6700 & 7600 & 8900 & 12200 \\
\hline \multirow{2}{*}{$\begin{array}{l}\text { "Uralelectrotyazhmash- } \\
\text { Gidromash", Ekaterinburg }\end{array}$} & & 390 & 290 & 750 & 550 & 820 & 800 & 1300 & 1010 & 1900 & 1400 \\
\hline & \multicolumn{2}{|c|}{$\mathrm{SC}$} & 1720 & 2200 & 2900 & 4200 & 4300 & 5600 & 5500 & 8500 & 8250 & 10600 \\
\hline \multirow{2}{*}{$\begin{array}{l}\text { Production group "Transformer", } \\
\text { Podolsk }\end{array}$} & & 420 & 270 & 750 & 530 & 1150 & 870 & 1400 & 1240 & 2000 & 1600 \\
\hline & \multicolumn{2}{|c|}{$\mathrm{SC}$} & 2100 & 1970 & 3700 & 3700 & 5700 & 5600 & 6700 & 7600 & 8900 & 10800 \\
\hline \multirow{2}{*}{$\begin{array}{l}\text { Electroshield, } \\
\text { Chekhov }\end{array}$} & & 390 & 280 & 750 & 520 & 1150 & 750 & 1500 & 1000 & 1950 & 1400 \\
\hline & \multicolumn{2}{|c|}{ SC } & 1740 & 1970 & 3040 & 3700 & 4260 & 5400 & 6350 & 7600 & 8700 & 10600 \\
\hline \multirow{6}{*}{$\begin{array}{l}\text { Requirements of European energy } \\
\text { efficiency standards HD } 428, \\
\text { HD } 538\end{array}$} & & $\mathrm{~A}^{\prime}$ & \multirow{3}{*}{440} & 320 & \multirow{3}{*}{820} & 650 & \multirow{3}{*}{1150} & 930 & \multirow{3}{*}{1500} & 1300 & \multirow{3}{*}{2000} & 1700 \\
\hline & & $\mathrm{B}^{\prime}$ & & 260 & & 530 & & 750 & & 1030 & & 1400 \\
\hline & & $\mathrm{C}^{\prime}$ & & 210 & & 425 & & 610 & & 860 & & 1100 \\
\hline & \multirow[t]{3}{*}{$\mathrm{SC}$} & A & & 1750 & & 3250 & & 4600 & & 6500 & & 10500 \\
\hline & & B & 2000 & 2150 & 3500 & 4200 & 4900 & 6000 & 7300 & 8400 & 10000 & 13000 \\
\hline & & $\mathrm{C}$ & & 1475 & & 2750 & & 3850 & & 5400 & & 9500 \\
\hline
\end{tabular}

short circuit. The standard HD 428.1 for oil transformers allow three wastage rates of short circuit $(\mathrm{A}, \mathrm{B}, \mathrm{C})$ and three wastage rates of idling ( $\left.\mathrm{A}^{\prime}, \mathrm{B}^{\prime}, \mathrm{C}^{\prime}\right)$.

\section{References}

[1] B.I. Kudrin, Power supply of industrial enterprises (Moscow: Interment Engineering) 672 (2006)

[2] V.P. Kalyavin, L.M. Rybakov, Reliability and diagnostics of electrical installations (Yoshkar-Ola: Mar. State University Press) 348 (2000)

[3] E.A. Konyukhova, Power supply (Moscow: Publishing House MEI) 502 (2014)

[4] E.A. Konyukhova, Reliability of power supply to industrial enterprises (Moscow: NTF Energoprogress) 92 (2001)

[5] Yu.B. Kozakov, A.B. Kozlov, A.V. Korotkov, Accounting for changes in no-load losses of transformers in the period of service life when calculating losses in distribution networks. Electrical Engineering. 5, (2006)

[6] O.V. Fedorov, Some features of the structure of internal power supply systems. Reliability and safety of energy. 3(30), 30-33 (2015)

[7] A.V. Korotkov, V.Ya. Frolov, The results of power measurements of no-load losses of transformers with different service life. Electrician. 8, (2011)

[8] E.I. Gracheva, O.V. Naumov, R.R. Sadykov, Accounting for no-load losses of transformers during operation when calculating electricity losses in distribution networks. News of higher educational institutions. Power problems. 1-2, 53-63 (2016)

[9] E.I. Gracheva, A.R. Safin, A.V. Shagidullin, Modeling of the influence changes in electrical equipment parameters on the value of the equivalent resistance the intrashop power supply systems. Elektrika. 7, 2-6 (2013)

[10] S.D. Lizunov, A.K. Lokhanin, Problems of modern transformer in Russia. Electricity. 8, (2000)

[11] N.V. Golubtsov, O.V. Fedorov, Electrotechnical complexes and systems of enterprises as objects of energy saving Electrical apparatuses and electrotechnical complexes and systems: materials of Int. Scientific Practical Conf. (Ulyanovsk: USTU) 222-226 (2012)

[12] O.V. Fedorov, Assessment of influence parameters of electric equipment at a size of losses the electric power in intra factory networks of low voltage 2nd Int. Conf. on Industrial Engineering, Applications and Manufacturing. CFP16F42-ART. DOI: 10.1109/ICIEAM.2016.7911463 (2016)

[13] E.I. Gracheva, O.V. Naumov, R.R. Sadykov, T.A. Serpionova, Modeling the parameters of functional characteristics of workshop networks Technical sciences - from theory to practice: materials of the LII Intern. Scientific Practical Conf.(Novosibirsk: Ed/ ANS «SibAK») 105-114 (2015)

[14] HD 428. Three-phase distribution transformers with an operating frequency of $50 \mathrm{~Hz}$ from 50 to $2500 \mathrm{kVA}$ with oil cooling and a maximum voltage of not higher than $36 \mathrm{kV}$.

[15] HD 538. Three-phase distribution transformers with an operating frequency of $50 \mathrm{~Hz}$ from 100 to $2500 \mathrm{kVA}$ with oil cooling and a maximum voltage not higher than $36 \mathrm{kV}$. 